\title{
A Simple Method Allowing Students to Improve Their 3-D Visualization Skills
}

Dr. Dan G. Dimitriu, San Antonio College

Dan G. Dimitriu has been practicing engineering since 1970 and taught engineering courses concurrently for more than 20 years at various institutions. In 2001, he joined San Antonio College full-time as the Coordinator of its Engineering program. He has been involved with several engineering societies and became a member of the Two-year College Division of ASEE in 2002. His research interests are in engineering graphics, 3-D Visualization, fuel cells, plastics, and engineering education. He received the 2015 Presidential Award for Excellence in Science, Mathematics, and Engineering Mentoring.

\section{Miss Dana Corrina Dimitriu}

Dana Dimitriu is a third-year mechanical engineering student at the University of Texas at San Antonio. She is currently working on receiving her bachelor's degree in Mechanical Engineering with a minor in Psychology. She has interests in biomechatronics, prosthetics, 3D visualization, and graphic design. 


\title{
A Simple Method to Help Students Improve 3-D Visualization Skills
}

\begin{abstract}
Spatial visualization skills and attention to detail can be effectively improved using various specialized methods. Starting in the 1990's multiple researchers observed that improving 3-D visualization leads to better performance in engineering graphics and in most other engineering coursework resulting in improved retention and graduation rates. The majority of the 3-D visualization exercises currently being used by students in Design and Graphics classes present the objects in isometric views already in 3-D, asking the viewer to create multiple views, fold patterns, manipulate, reflect, or rotate them. Other exercises present the objects in incomplete multi-view projections and ask the students to add missing lines. The newly proposed method uses a different approach. It uses the standard multi-view projections to show a number of rectangular bricks arranged in various patterns. The viewer must count the exact number of bricks that form the structure. To do this the viewer must visualize each brick in its 3-D arrangement and count it only once despite the fact that the same brick may show up in more than one view. The new method was used for over nine years with demonstrated success for students with a wide variety of visualization skills. It is intended as a tool to help Engineering, Architecture, and Art students and faculty who want to increase their 3-D visualization skills and improve their attention to detail.
\end{abstract}

Introduction

Preparing students for successful STEM careers requires a variety of math, science, and engineering courses. Most of these courses, particularly the engineering ones, consider the ability to visualize in a 3-D environment an essential skill. It has been shown to be a good predictor of success in several engineering and technology-related disciplines [1] - [5]. An early study from I. M. Smith in 1964 [6] identified at least 84 career areas for which spatial skills are important. Women, underrepresented minorities, and non-traditional students have been found to have somewhat lower spatial visualization skills affecting their performance in STEM fields but after specialized training, they showed improvements in their skills [7] - [10]. A study by Uttal, et al. [11] published in 2013 found that more than 200 studies on improvement of spatial skills demonstrated that students who receive extensive training and practice on spatiallyrelevant skills showed increased visualization skills.

Training and testing were the focal point of numerous studies [12] - [16] and they cover multiple methods to challenge students to visualize objects and patterns in various settings. All have been proven to help the students improve their spatial skills but without one being universally accepted to be $100 \%$ effective. They all demonstrated various degrees of success depending on students' background, gender, resources, socio-economic status, time spent on practicing, and, of course, their level of interest. As a result, the more variety of methods is available, the more choices the faculty and students will have to select the most appropriate method for their particular situation. 


\section{Background}

About a year after the publication of the "A, B, See... in 3D" book [17], a new book followed with a new kind of exercises. The old idea of cubes arranged in various shapes and positions was initially used to create new challenges to improve students' spatial skills. One major problem though was that cubes, presenting the same image in each standard view of orthographic projections, were not the best suited for correct individual cubes identification between adjacent views.

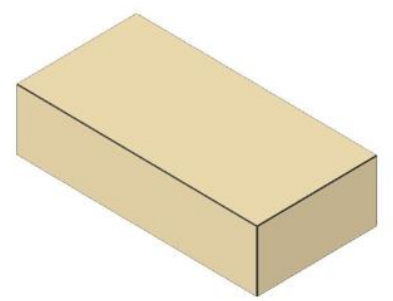

Figure 1: Sample Brick

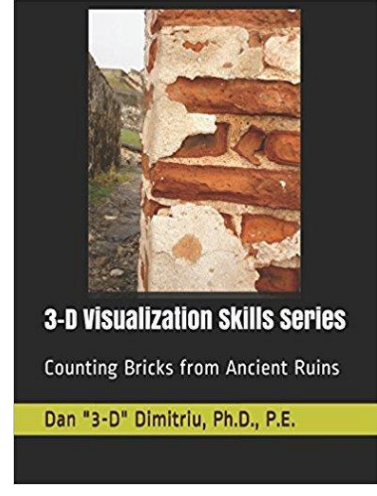

Figure 2: The book with brick exercises

The best solution was found to be a 1 x 2 x 4 brick (Figure 1).

It provided the ability to develop challenging 3-D arrangements and with that, the new method started to take shape. A selection of several early exercises was published in a book format (Figure 2) in 2017 [18] that had a very good reception. As a result of the feedback, the book will be followed soon by another one with more advanced exercises and challenges so the method can reach a larger audience interested in improving their 3-D visualization skills.

\section{The Method}

The method consists of images presenting unfinished brick walls in the three standard views of an orthographic projection of the wall arranged in various configurations and asking the viewer to count all the bricks. The images do not include a pictorial view of the wall so the method is expecting the viewers to construct the 3-D image of the wall from the three given views. Appendix A is showing a sample of the method. The wall structure complexity can be ranked based on the number of corners from zero to five depending on the number of corners the wall has. Zero means the wall has no corners and five means it has five corners. The number of bricks in the wall can range from three up to forty. Anything above forty bricks will improve mainly the attention to detail without having a major effect on 3-D visualization skills. The timing of the test is recommended to be established at 10 minutes for all levels of complexity. This requirement helps the students to increase gradually their speed of making correlations between the given views. This, in turn, increases their ability to visualize the whole wall in 3-D.

Multi colored LEGO 2 × 4 bricks (Figure 3) are the best standard manipulatives to be used in the initial stages of the method to help students with visualization, but at a later stage, the students must be encouraged to figure out the wall structure and count the bricks without manipulatives. This is when they will start developing their spatial ability and improve their abstract thinking. 


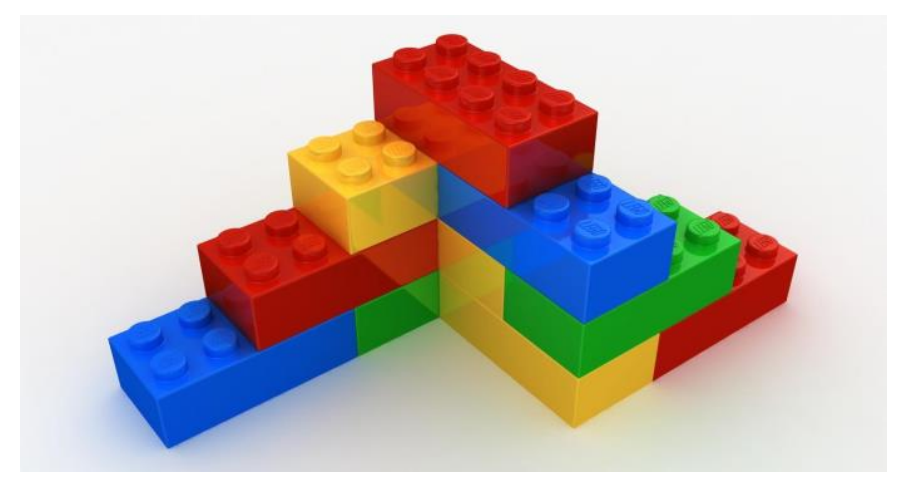

Figure 3: Wall simulation with LEGO bricks

There are two cardinal rules that those who try to implement this method have to follow. The first rule is that every brick must appear, even partially, in at least one view. The second rule is, there can be no holes in the wall. These two rules eliminate the guesswork from the counting. The viewers should have the confidence that there are no missing bricks in the remaining wall and that every brick is visible in at least one of the given views.

Results

For the last three semesters, the new visualization training method was included in two sections of an Engineering Graphics course. The course is a 3-Credit (2 lecture hours, 4 lab contact hours) course that introduces students during the first half of the semester to the basic rules of Engineering Graphics and, in parallel, they learn to apply them in AutoCAD 2-D. During the second half of the semester, the students learn the 3-D Parametric Modeling Program Inventor and apply everything the learned in the first half to the new 3-D environment. Enrollment was capped at 32 students per semester due to lab capacity and every semester we had full enrollment, so a total of 96 students started this type of training. The average enrollment of women in these classes was between 10 to $18 \%$.

During the hand-drawing periods at the beginning of the course, the students solved a variety of assignments designed to make them familiar with the basic concepts of multi-view orthographic projections generated by the unfolded glass box. Right at the end of this period, the 3-D visualization training was introduced in parallel with the rest of the Engineering Graphics subjects such as dimensioning, sectioning, auxiliary views, and pictorials.

In each section of the class, the Purdue Spatial Visualization Test: Visualization of Rotations (PSVT: VR) was administered during the first and last day of class. The results from the test showing the average number of correct answers per test are presented in Table 1.

The observed results are similar to published results from other studies describing the PSVT: VR but the fact that the test is administered at both ends of the course could be used only to evaluate the specific effect of the entire course and does not reveal the effectiveness of the new method in particular. 
Table 1 - Participating students in PSVT: VR

\begin{tabular}{|c|c|c|c|c|c|c|}
\hline & $\begin{array}{c}\text { All } \\
\text { Students }\end{array}$ & Average & \# Males & Average & \# Females & Average \\
\hline First Day Results & 96 & 19.18 & 78 & 20.09 & 18 & 15.27 \\
\hline Last Day Results & 61 & 24.99 & 55 & 25.17 & 6 & 23.35 \\
\hline
\end{tabular}

In order to evaluate the effect of the new method, the following strategy has been used. Just before the start of the training period, both classes took a short version (12 slides), LPT ("Letter Projection Test") described in a previous paper [16] and available for download from the book publisher. Right after, they had to solve a level 3 wall problem showing 25 bricks. For the LPT each misidentified letter counted as one error. Each brick that was counted below or above the exact number of bricks was counted as one error so, if there was a count of 22 or 28 bricks when the correct number was 25 it counted as 3 errors. None of the initial test results were discussed in class afterward. Then both classes went through the new method training consisting of three levels of wall problems followed by detailed analysis and discussions. At the end of this 3-D training, both classes took the LPT with the same slides but in a different sequence and a level 4 wall problem, with the same number of bricks as the initial level 3 problem. The number of participating students is different from the number of students starting the class to account for the students withdrawn during the first two weeks of classes. Table 2 compares the number of errors made by the students and the averages in each test.

Table 2 - Results of the method evaluation

\begin{tabular}{|l|l|l|l|}
\hline & Total & Males & Females \\
\hline Number of Students & 84 & 72 & 12 \\
\hline LPT Errors (Initial Test) & 389 & 332 & 57 \\
\hline Average Error & 4.63 & 4.61 & 4.75 \\
\hline Wall Problem Errors (Initial Test) & 410 & 329 & 81 \\
\hline Average Error & 4.88 & 4.57 & 6.75 \\
\hline LPT Errors (End Test) & 146 & 128 & 18 \\
\hline Average Error & 1.74 & 1.78 & 1.50 \\
\hline Wall Problem Errors (End Test) & 39 & 30 & 9 \\
\hline Average Error & 0.46 & 0.42 & 0.75 \\
\hline \% Improvement (LPT/Wall) & $62 / 90$ & $61 / 91$ & $68 / 89$ \\
\hline
\end{tabular}


Although the number of students involved in this training was relatively small, both tests demonstrate evident improvements in students' 3-D visualization skills. This should be just a start for future studies, evaluations, and analyses that will be necessary to improve and further develop the new method.

\section{A Student's Reflection On This Method}

This method has been proven to help many students. To further emphasize the importance of this method and its application, a student was asked to coauthor this paper, specifically this part of the paper, to allow for an accurate account of the method's effect. The student in this section, to more appropriately convey personal accounts, uses first person.

Spatial awareness is an extremely necessary skill to succeed in the field of engineering but unfortunately, one of the least emphasized skills is 3-D visualization. The method presented in this paper can be used in any setting but many of my colleagues have never heard of this topic. The initial moment of contact is the most difficult for students who do not have very much experience with hands-on activities or 3-D visualization exercises. Through constant immersion, it becomes easier to visualize a 3-D environment and one's confidence improves. Practice always leads to proficiency.

When I started using the exercises in the book, I could not correlate multiple images to create a cohesive 3-D image. The introduction of LEGO bricks has seems to help me solve the problems. Piecing together LEGO bricks to resemble the way the walls are shown in the given projections allowed me to combine the information being relayed in a 2-D format and build a virtual 3-D image.

After practicing this method for a while, it has had the strongest impact on me in the beginning stages by helping me overcome the initial difficulties of the 3-D visualization process.

Following the LEGO phase, the absence of an isometric representation of the bricks arranged in the wall formations obligated me to create a mental image of the wall based only on the given views. It appears that it is the essence of building lasting 3-D visualization skills. For advanced students in engineering, arts, or architecture programs, who have already developed spatial skills, I believe the method is beneficial mainly for improving their attention to details.

Thus as seen in the accounts of the student, this method proves to help the student better understand how to visualize two-dimensional representations in a three-dimensional space. Additionally, the method can be used across multiple disciplines and the majority of the students who have used it reported significant improvements in their spatial visualization skills.

Conclusions

This new method was used for over nine years in conjunction with other established methods dedicated to improving 3-D visualization skills. A more in-depth study of the method has been done in the last three semesters to validate its success for students with a wide variety of visualization skills.

The timed exercises call for a rapid succession of correlations between views, which no other method provides. The students must observe and analyze each brick occurrence in every view 
observing if the brick appears in full or partial view. Only then they can decide if the respective brick appears once, twice, or three times in the given views and count it only once. This increases their attention to details, improves their abstract thinking and, at the same time, develops their ability to visualize the wall structure in 3-D. Many times, particularly at the beginning of this training, they cannot make the distinction easily but, with practice, they definitely can improve. For the last three semesters, an anonymous short survey was administered at the end of this special 3-D visualization training period to evaluate students' opinions regarding the new training method. The results are presented in Table 3. The survey shows that the students had generally a positive view of this new method and that they considered this training as being helpful to improve their spatial ability.

Table 3 - Survey results

\begin{tabular}{|c|c|c|c|c|c|}
\hline Question/Choice & Extremely & Somewhat & $\begin{array}{c}\text { Not very } \\
\text { much }\end{array}$ & $\begin{array}{c}\text { Not at } \\
\text { all }\end{array}$ & $\begin{array}{c}\text { Total } \\
\text { Responses }\end{array}$ \\
\hline $\begin{array}{c}\text { Do you consider 3D visualization } \\
\text { skills important for engineers? }\end{array}$ & $79 \%$ & $21 \%$ & 0 & 0 & 84 \\
\hline $\begin{array}{c}\text { Do you consider the "Brick Wall" } \\
\text { exercises challenging }\end{array}$ & $45 \%$ & $48 \%$ & $7 \%$ & 0 & 84 \\
\hline $\begin{array}{c}\text { Do you consider that the "Brick } \\
\text { Wall" exercises improved your 3D } \\
\text { visualization skills? }\end{array}$ & $40 \%$ & $46 \%$ & $12 \%$ & $2 \%$ & 84 \\
\hline $\begin{array}{c}\text { Would you recommend the "Brick } \\
\text { Wall" for training to improve 3D } \\
\text { visualization skills? }\end{array}$ & $41 \%$ & $44 \%$ & $11 \%$ & $4 \%$ & 84 \\
\hline
\end{tabular}

\section{References}

[1]. S. Strong, \& R. Smith, "Spatial visualization: Fundamentals and trends in engineering graphics", Journal of Industrial Technology, 18(1), 1-6., 2001.

[2]. J.V. Ernst, D. Lane, and A.C. Clark, "Pictorial Visual Rotation Ability of Engineering Design Graphics Students", Proceedings of ASEE Annual Conference, Indianapolis, IN, 2014.

[3]. W. F. Kelly, T. J. Branoff, and A. C. Clark, "Spatial Ability Measurement in an Introductory Graphic Communications Course", Proceedings of ASEE Annual Conference, Indianapolis, IN, 2014..

[4]. P. Katsioloudis, V. Jovanovic, and M. Jones, "A Comparative Analysis of Spatial Visualization Ability and Drafting Models for Industrial and Technology Education Students”, Journal of Technology Education, Vol. 26, No. 1, Fall 2014.

[5]. N. L. Veurink, and A. J. Hamlin, "Spatial Visualization Skills: Impact on Confidence and Success in an Engineering Curriculum”, Proceedings of ASEE Annual Conference, Vancouver, IN, 2011 
[6]. I. M. Smith, "Spatial ability - Its educational and social significance", University of London, London, 1964

[7]. B. J. Gimmestad, "Gender differences in spatial visualization and predictors of success in an engineering design course", Proceedings of the National Conference on Women in Mathematics and the Sciences, St. Cloud, MN, 133-136, 1989.

[8]. P. Connolly, L. V. A. Harris, and M. Sadowski, "Measuring and Enhancing Spatial Visualization in Engineering Technology Students", Proceedings of ASEE Annual Conference, Austin Texas, 2009.

[9]. S. A. Sorby, "Educational research in developing 3-D spatial skills for engineering students", International Journal of Science Education, Vol. 31, No. 3, pp. 459-480, 2009.

[10]. J. Rodriguez and L. G. Rodriguez, "Effect of Demographics on the Spatial Visualization Skills in 2D and 3D Course Offerings", Proceedings of ASEE Annual Conference, Columbus, OH, 2017

[11]. D. H. Uttal, N. G. Meadow, E. Tipton, L. L. Hand, A. R. Alden, N. S. Newcombe, and C. Warren, "The Malleability of Spatial Skills: A Meta-Analysis of Training Studies", Psychological Bulletin, Vol. 139, No. 2, 352-402, 2013.

[12]. S. A. Sorby, A. F. Wysocki, and B. J. Baartmans, "Introduction to 3D Spatial Visualization: An Active Approach" (Book and CD), Published by Delmar Cengage Learning, 2003.

[13]. Lei Gu, "Using Physical Models in Improving Low Visualizers' Spatial Visualization Skills", Proceedings of ASEE Annual Conference, Columbus, OH, 2017.

[14]. E. S. Uria and M. G. Mujika, "Teaching Part Visualization in First-Year Engineering Courses: Methodology for Part Visualization Problem Solving”, Proceedings of ASEE Annual Conference, Pittsburgh, PA, 2008.

[15]. V. LeBow, M. L. Bernhardt-Barry, and J. Datta, "Improving Spatial Visualization Abilities Using 3D Printed Blocks", Proceedings of ASEE Annual Conference, Salt Lake City, UT, 2017.

[16]. D. G. Dimitriu, “A New Way to Help Students Improve 3-D Visualization”, Proceedings of ASEE Annual Conference, New Orleans, LA, 2016.

[17]. D. G. Dimitriu, “A, B, See... in 3D: A Workbook to Improve 3-D Visualization Skills”, Morgan and Claypool Publishers, 2015

< http://www.morganclaypool.com/doi/abs/10.2200/S00669ED1V01Y201508ENG025? journalCode=eng >

[18]. D. G. Dimitriu, "Counting Bricks from Ancient Ruins: Improve Your 3D Visualization Skills”, Amazon, 2017

$\langle\underline{\text { https://www.amazon.com/Counting-Bricks-Ancient-Ruins-Visualization/dp/1521520003 }}>$ 


\section{Sample}

Count the remaining bricks left in the displayed ruin. When counting the bricks the viewer must identify correctly each brick in every view since the same brick may show up in more than one view!
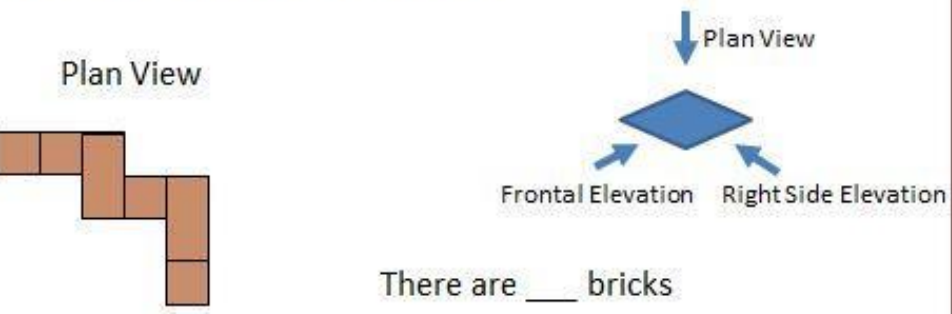

There are bricks

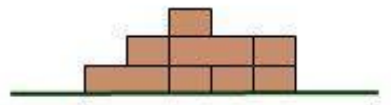

Frontal Elevation

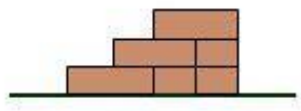

Right Side Elevation

\section{Solution}

Count the remaining bricks left in the displayed ruin. When counting the bricks the viewer must identify correctly each brick in every view since the same brick may show up in more than one view!
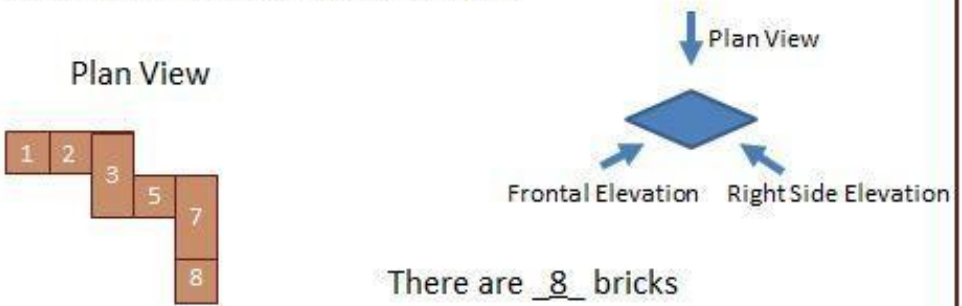

There are _ 8 _bricks

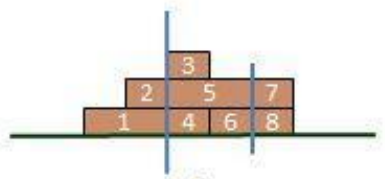

Frontal Elevation

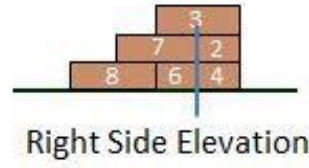

